\title{
Job satisfaction and burnout among Palestinian nurses
}

\author{
L. Abushaikha ${ }^{1}$ and H. Saca-Hazboun ${ }^{2}$
}

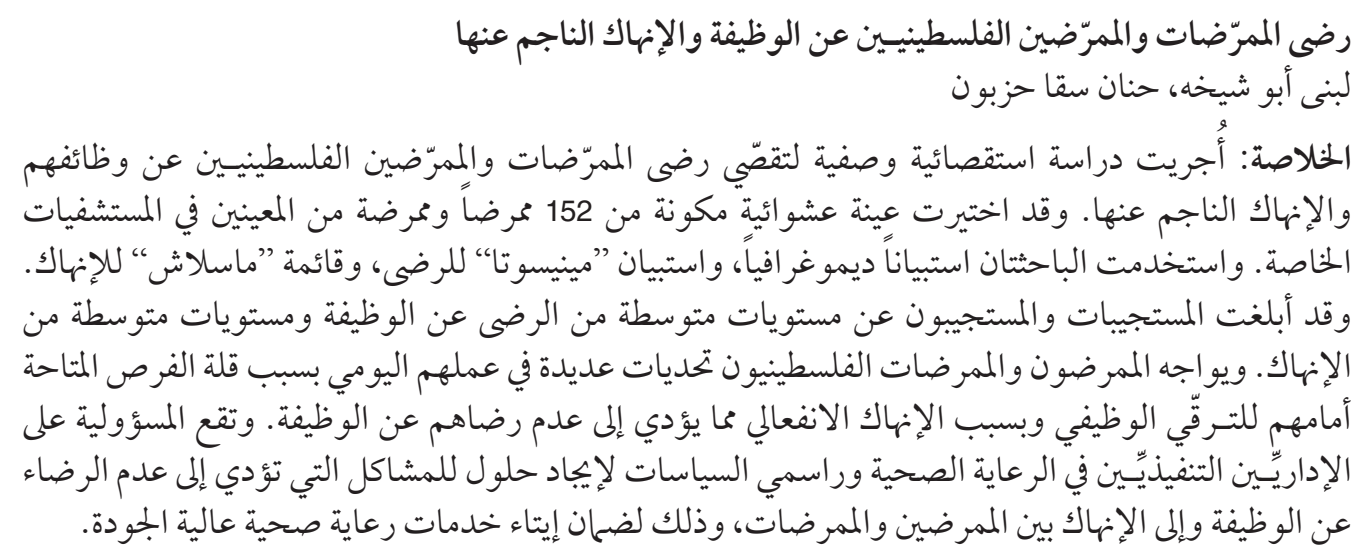

ABSTRACT An exploratory descriptive study design was used to investigate job satisfaction and burnout among Palestinian nurses. A random sample of 152 nurses was recruited from private hospitals. The instruments included a demographic questionnaire, the Minnesota satisfaction questionnaire and the Maslach burnout inventory. Respondents reported moderate levels of job satisfaction and moderate burnout. Palestinian nurses face many challenges in their daily work due to decreased chances of job advancement and emotional exhaustion which may lead to job dissatisfaction. Health care administrators and policy-makers have a responsibility to find solutions to problems that cause job dissatisfaction and burnout among nurses to ensure the delivery of quality health care services.

\section{Satisfaction au travail et épuisement professionnel chez les infirmières palestiniennes}

RÉSUMÉ Un modèle d'étude descriptive et exploratoire a été utilisé pour enquêter sur la satisfaction au travail et l'épuisement professionnel chez les infirmières palestiniennes. Un échantillon aléatoire de 152 infirmières a été recruté dans des hôpitaux privés. Les instruments utilisés comprenaient un questionnaire démographique, le questionnaire MSQ (Minnesota satisfaction questionnaire) et l'échelle MBI (Maslach burnout inventory). D'après les déclarations des personnes interrogées, leurs niveaux de satisfaction au travail et d'épuisement professionnel étaient moyens. Les infirmières palestiniennes sont confrontées à de nombreuses difficultés dans leur travail quotidien en raison de la réduction des possibilités d'avancement et de l'épuisement émotionnel qui peut conduire à l'insatisfaction professionnelle. II incombe aux administrateurs et aux décideurs du secteur des soins de santé de trouver des solutions aux problèmes à l'origine d'une insatisfaction et d'un épuisement professionnels parmi les infirmières, afin de garantir la prestation de services de soins de santé de qualité.

\footnotetext{
${ }^{1}$ Faculty of Nursing, Jordan University of Science and Technology, Irbid, Jordan (Correspondence to L. Abushaikha: lub2001@just.edu.jo).

${ }^{2}$ School of Nursing, University of Bethlehem, Bethlehem, Palestine.

Received: 19/02/06; accepted: 06/08/06
} 


\section{Introduction}

Nursing is a stressful profession that deals with intense human aspects of health and illness [1-3]. Consequently, the stressful nature of nursing can ultimately lead to job dissatisfaction and burnout [2-7]. Among health care professionals, nurses have been found to be most prone to burnout [8]. Job satisfaction and burnout among health care providers are important issues since they affect turnover rates, staff retention and ultimately the quality of patient care [9-11].

Job satisfaction has been described as the degree of positive affective orientation toward a job $[2,4,5]$. Burnout has been defined as a syndrome of physical and emotional exhaustion, involving the development of negative self-concept, negative job attitudes and loss of concern for clients [8]. Job satisfaction and burnout have been studied in several industrial countries for decades, but have only been investigated in some developing countries in the past 2 decades [3,12-14]. Therefore, the phenomena of job satisfaction and burnout in the Arab culture remain poorly researched and the majority of the work remains unpublished (Y. Abu-Dahrieh, 1989; A. Abu-Ajamieh, 1991; H. Hamdan, 1993; Bolad et al., 2000, unpublished data).

Many factors are reported to affect job satisfaction among Arab nurses, such as workload, incentives, job security, relationships with superiors and peers and organizational structure [3,12-14]. Burnout has been associated with high employment turnover, excessive absenteeism, negative job attitudes, low morale and a deterioration in idealism towards helping others [2,8,15-20].

The aim of this study was to explore the phenomena of job satisfaction and burnout among Palestinian nurses. We examined 2 questions: What levels of job satisfaction and burnout do Palestinian nurses report?
What are the relationships between demographic variables, job satisfaction and burnout?

\section{Methods}

A descriptive correlational study design was used based on Maslow's theory of hierarchy of needs and Herzberg's theory of hygienic and motivation factors $[21,22]$.

\section{Sample}

A random sample of 255 hospital nurses was selected from 5 hospitals. Completed surveys were returned from 152 participants, a response rate of $59.6 \%$. The study was conducted between 1 January and 31 March, 2000 at 4 private hospitals in the Palestinian Territories (Al-Muhtasseb hospital in Hebron, Caritas hospital in Bethlehem, Augusta Victoria hospital in Jerusalem and Al-Itihad hospital in Nablus) and 1 United Nations Relief and Works Agency (UNRWA)-affiliated hospital in Qalqilia. The distribution of the study sample was: Al-Itihad, 20 nurses; Caritas, 50 nurses; Augusta Victoria, 34 nurses; Al-Muhtasseb, 19 nurses; and Qalqilia, 29 nurses. Data on the characteristics of non-respondents were not available.

\section{Data collection}

Respondents completed a 3-part survey that included a demographic questionnaire, the Maslach burnout inventory (MBI), and the Minnesota satisfaction questionnaire (MSQ) [22,23]. The demographic questionnaire measured variables that included age, sex, marital status, number of children, education, length of experience, job position, adequacy of income, other employment and graduate studies.

Burnout was measured using the MBI, which comprises 3 subscales-emotional 
exhaustion, depersonalization and personal accomplishment-with 22 items and a 6-point response format. Higher scores on the emotional exhaustion and depersonalization scales indicate more burnout, while higher scores on the perceived accomplishment scale indicate less burnout.

The MSQ contains 100 items and measures 20 aspects of work using 20 subscales plus 1 general satisfaction score, which comprises 1 item from each scale. The MSQ has a 5-point scale ranging from 1 (very dissatisfied) to 5 (very satisfied). Scores $<26$ represent low satisfaction, scores 26-75 represent average satisfaction and scores $>75$ represent high satisfaction.

Ethical permission to conduct the study was obtained from hospital directors prior to data collection. Surveys were distributed to the nurses while they were on the job. Coding and aggregate reporting were used to eliminate respondent identification and ensure anonymity.

\section{Data analysis}

The data were analysed using the $S A S$, version 6.03, DOS program. Descriptive and inferential statistics were used to analyse responses to the surveys.

\section{Results}

\section{Sample characteristics}

The age of participants ranged from 24 to 58 years, mean 30.9 [standard deviation (SD) 7.1] years. The majority of respondents were female $(73.7 \%)$ and married $(61.8 \%)$ (Table 1). Just over 50\% had nursing certificates.

No statistically significant relationships were found between education level, job satisfaction and burnout. Mean duration of experience was 9.1 (SD 6.7) years. The average respondent had been working for
5.4 years in the current position and 7.5 years in the current setting. The majority of respondents $(80.3 \%)$ worked as staff nurses, $12.5 \%$ were head nurses and $7.2 \%$ were assistant head nurses. Most (59.2\%) reported that their incomes were inadequate to meet their needs and that they did not have any other employment (94.7\%). In this sample,

Table 1 Characteristics of the study sample of nurses $(n=152)$

\begin{tabular}{|c|c|c|}
\hline Characteristic & No. & $\%$ \\
\hline \multicolumn{3}{|l|}{ Age (years) } \\
\hline 20-24 & 26 & 17.1 \\
\hline $25-29$ & 46 & 30.3 \\
\hline $30-34$ & 40 & 26.3 \\
\hline $35-39$ & 20 & 13.2 \\
\hline$>39$ & 20 & 13.1 \\
\hline \multicolumn{3}{|l|}{ Sex } \\
\hline Male & 40 & 26.3 \\
\hline Female & 112 & 73.7 \\
\hline \multicolumn{3}{|l|}{ Marital status } \\
\hline Married & 94 & 61.8 \\
\hline Single & 56 & 36.8 \\
\hline Divorced & 2 & 1.3 \\
\hline \multicolumn{3}{|l|}{ No. of children } \\
\hline 0 & 65 & 42.8 \\
\hline $1-3$ & 58 & 38.2 \\
\hline $4-6$ & 25 & 16.4 \\
\hline $7+$ & 4 & 2.6 \\
\hline \multicolumn{3}{|c|}{ Level of education } \\
\hline Certificate & 79 & 52.0 \\
\hline Diploma & 32 & 21.0 \\
\hline Bachelor & 41 & 27.0 \\
\hline \multicolumn{3}{|c|}{ Pursuing higher education } \\
\hline Yes & 48 & 31.6 \\
\hline No & 104 & 68.4 \\
\hline \multicolumn{3}{|c|}{ Years of experience } \\
\hline $0-3$ & 25 & 16.4 \\
\hline $4-6$ & 41 & 27.0 \\
\hline $7-9$ & 25 & 16.4 \\
\hline $10-13$ & 23 & 15.1 \\
\hline$>13$ & 38 & 25.0 \\
\hline
\end{tabular}


$31.6 \%$ of respondents were pursuing graduate education.

\section{Job satisfaction}

Most nurses in this study (84.2\%) reported moderate job satisfaction (Table 2). Moral values $(55.9 \%)$ and social services $(55.9 \%)$ were areas of high satisfaction. Areas of moderate satisfaction included authority $(85.5 \%)$ and responsibility $(78.3 \%)$, while advancement (41.4\%) and company policies and practices (28.9) were areas of low satisfaction. Significant differences were found between nurses reporting adequate and inadequate incomes on ability utilization $(t=2.41, P<0.001)$, advancement $(t$ $=2.60, P=0.01)$, company policies and practices $(t=2.72, P<0.01)$, compensation $(t=3.77, P<0.01)$, responsibility $(t=2.18$, $P=0.03)$, working conditions $(t=2.15$, $P=0.03)$ and general job satisfaction $(t=$ $2.14, P=0.03)$. Years of experience had a significant effect on independence $(F=$ 2.46, $P=0.04)$, while place of employment significantly affected several aspects of job satisfaction (Table 3). Number of children affected security $(F=4.96, P<0.001)$, while general satisfaction was affected by position $(F=4.16, P<0.001)$.

\section{Burnout}

When comparing burnout among nurses from the 5 hospitals, personal accomplishment was highest among nurses in the Caritas hospital (mean score 36.9) while it was the lowest among nurses in Al-Muhtasseb

Table 2 Distribution of the Minnesota satisfaction questionnaire scores ( $n=152$ nurses)

\begin{tabular}{|c|c|c|c|c|c|c|c|}
\hline \multirow[t]{3}{*}{ Subscale } & \multirow[t]{3}{*}{ Mean score (SD) } & \multicolumn{6}{|c|}{ Satisfaction } \\
\hline & & \multicolumn{2}{|c|}{ Low } & \multicolumn{2}{|c|}{ Moderate } & \multicolumn{2}{|c|}{ High } \\
\hline & & No. & $\%$ & No. & $\%$ & No. & $\%$ \\
\hline Ability utilization & $3.75(0.74)$ & 3 & 2.0 & 95 & 62.5 & 54 & 35.5 \\
\hline Achievement & $3.89(0.66)$ & 3 & 2.0 & 88 & 57.9 & 61 & 40.1 \\
\hline Activity & $3.97(0.60)$ & 3 & 2.0 & 86 & 56.6 & 63 & 41.4 \\
\hline Advancement & $2.64(1.04)$ & 63 & 41.4 & 76 & 50.0 & 13 & 8.6 \\
\hline Authority & $3.46(0.64)$ & 2 & 1.3 & 130 & 85.5 & 20 & 13.2 \\
\hline Company policies \& practices & $2.81(1.00)$ & 44 & 28.9 & 96 & 63.2 & 12 & 7.9 \\
\hline Compensation & $3.01(0.92)$ & 32 & 21.2 & 105 & 69.1 & 15 & 9.9 \\
\hline Co-workers & $3.86(0.69)$ & 3 & 2.0 & 97 & 63.8 & 52 & 34.2 \\
\hline Creativity & $3.44(0.74)$ & 10 & 6.6 & 118 & 77.6 & 24 & 15.8 \\
\hline Independence & $3.13(0.81)$ & 18 & 11.8 & 116 & 76.3 & 18 & 11.8 \\
\hline Moral values & $4.04(0.66)$ & 1 & 0.7 & 66 & 43.4 & 85 & 55.9 \\
\hline Recognition & $3.13(0.95)$ & 25 & 16.4 & 102 & 67.1 & 25 & 16.4 \\
\hline Responsibility & $3.31(0.77)$ & 11 & 7.2 & 119 & 78.3 & 22 & 14.5 \\
\hline Security & $3.18(0.85)$ & 22 & 14.5 & 113 & 74.3 & 17 & 11.2 \\
\hline Social services & $4.14(0.57)$ & 0 & 0.0 & 67 & 44.1 & 85 & 55.9 \\
\hline Social status & $3.35(0.78)$ & 14 & 9.2 & 112 & 73.7 & 26 & 17.1 \\
\hline Supervision: human relations & $3.23(0.98)$ & 23 & 15.1 & 100 & 65.8 & 29 & 19.1 \\
\hline Supervision: technical & $3.09(0.90)$ & 25 & 16.4 & 110 & 72.4 & 17 & 11.2 \\
\hline Variety & $3.15(0.77)$ & 17 & 11.2 & 115 & 75.7 & 20 & 13.2 \\
\hline Working conditions & $3.28(0.86)$ & 16 & 10.5 & 111 & 73.0 & 25 & 16.4 \\
\hline
\end{tabular}

$S D=$ standard deviation . 
Table 3 Variances in job satisfaction with respect to place of employment

\begin{tabular}{lcccc}
\hline Subscale & Sum of squares & Square mean & F-value & $P$-value \\
\hline Activity & 86.27 & 21.57 & 2.48 & 0.04 \\
Advancement & 504.43 & 126.11 & 5.14 & $<0.001$ \\
Authority & 172.89 & 43.22 & 4.7 & $<0.001$ \\
Company policies \& practices & 544.41 & 136.10 & 6.20 & $<0.001$ \\
Compensation & 357.07 & 89.27 & 4.62 & $<0.001$ \\
Co-workers & 186.39 & 46.60 & 4.13 & $<0.001$ \\
Creativity & 147.24 & 36.81 & 2.83 & 0.02 \\
Independence & 386.14 & 96.53 & 6.71 & $<0.001$ \\
Moral values & 120.25 & 30.06 & 2.95 & 0.02 \\
Recognition & 490.23 & 122.56 & 6.12 & $<0.001$ \\
Responsibility & 352.70 & 63.18 & 4.62 & $<0.001$ \\
Security & 399.67 & 99.92 & 6.27 & $<0.001$ \\
Social service & 174.91 & 43.73 & 6.22 & $<0.001$ \\
Supervision: human relations & 891.73 & 222.93 & 11.96 & $<0.001$ \\
Supervision: technical & 522.09 & 130.52 & 7.56 & $<0.001$ \\
Variety & 339.68 & 84.92 & 6.35 & $<0.001$ \\
Working conditions & 410.47 & 102.62 & 6.32 & $<0.001$ \\
General & 153.80 & 38.45 & 5.77 & $<0.001$ \\
\hline
\end{tabular}

(mean 27.1). Emotional exhaustion was highest among Qalqilia nurses (mean 27.9), while Caritas nurses had the lowest (mean 20.4). Finally, depersonalization was highest among Al-Itihad nurses (mean 7.7) and lowest among Caritas nurses (mean 2.8).

In general, nurses in this study reported moderate levels of burnout. They reported mostly low levels of personal achievement $(39.5 \%)$, moderate levels of emotional exhaustion $(38.8 \%)$ and low levels of depersonalization (72.4\%) (Table 4). A significant difference was found in depersonalization between nurses who reported adequate income and those who reported inadequate income $(t=-2.32, P=0.02)$ and between nurses who were married and those who were divorced $(F=6.43, P<0.001)$.

\section{Discussion}

It was interesting to find that participants reported moderate levels of both job satisfaction and burnout, which is contrary to the inverse relationship between the 2 concepts reported in the literature $[1-7,10-12,24]$. It seemed that moderate burnout did not

Table 4 Distribution of Maslach burnout inventory scores ( $n=152$ nurses)

\begin{tabular}{|c|c|c|c|c|c|c|c|}
\hline \multirow[t]{3}{*}{ Subscale } & \multirow[t]{3}{*}{ Mean score (SD) } & \multicolumn{6}{|c|}{ Burnout } \\
\hline & & \multicolumn{2}{|c|}{ Low } & \multicolumn{2}{|c|}{ Moderate } & \multicolumn{2}{|c|}{ High } \\
\hline & & No. & $\%$ & No. & $\%$ & No. & $\%$ \\
\hline Personal achievement & $34.14(9.44)$ & 60 & 39.5 & 42 & 27.6 & 50 & 32.9 \\
\hline Emotional exhaustion & 23.48 (10.23) & 36 & 23.7 & 59 & 38.8 & 57 & 37.5 \\
\hline Depersonalization & $5.42(5.61)$ & 110 & 72.4 & 28 & 18.4 & 14 & 9.2 \\
\hline
\end{tabular}

$S D=$ standard deviation . 
negatively affect the level of job satisfaction among Palestinian nurses working in private and UNRWA-affiliated hospitals.

In our study nurses in private health care settings were satisfied with their jobs, which confirms previous results concerning Palestinian nurses [12,25,26; Y. Abu-Dahrieh 1989; A. Abu-Ajamieh, 1991; H. Hamdan, 1993; Bolad et al., 2000, unpublished data]. These results may be attributed to structural and functional differences between public and private hospitals. It may be that private and UNRWA-affiliated hospitals offer better facilities, more incentives and superior working conditions to nurses compared with government hospitals, which usually have limited financial and human resources to offer to employees. The disparity between government and private health care settings continues to be an issue of debate and warrants more in-depth investigation.

The nurses in our sample also reported that many factors contributed to their job satisfaction, such as moral values, social services authority, responsibility and creativity, which is in agreement with previous findings $[12,25,26$; Y. Abu-Dahrieh 1989; A. Abu-Ajamieh, 1991; H. Hamdan, 1993; Bolad et al., 2000, unpublished data]. Conversely, nurses reported that lack of career advancement opportunities and unsupportive hospital policies and practices contributed to job dissatisfaction, which is congruent with Hamdan's results.

The results of this study emphasize the influence of job and individual characteristics on job satisfaction and burnout $[3,6,20]$. The study results support Herzberg's and Maslow's theories [21,22] which identified recognition, achievement, the nature of the work, responsibility and advancement as characteristics that are strong determinants of job satisfaction and burnout.

Moderate emotional exhaustion reported by nurses in this sample is congruent with results of previous research $[2-7,20]$. Obviously, individual differences between the 5 hospitals were detected in this study, which supports the idea that different policies and practices can affect burnout levels. Moderate emotional exhaustion among study participants, who were mostly young adults aged 25-29 years and had been on the job for an average of 9 years, supports the notion that burnout is a "global" nursing phenomenon that results from stress and work overload in everyday practice $[3-7,14,20]$.

Participants also reported low levels of personal achievement and depersonalization. Perhaps the feeling of low personal achievement was the motive for pursuing higher education in one-third of the sample. Furthermore, low depersonalization in this sample may have contributed to a moderate sense of job satisfaction. Nurses viewed their relationships with their clients as positive ones that nurtured mutual care and concern, especially under harsh social and political circumstances. They felt that they were significant contributors to the health and wellbeing of the Palestinian people, who live in daily turmoil. Moreover, it was not surprising to find that the nurses who reported inadequate incomes and were divorced felt more depersonalized. This finding attests to the influence of social norms and peer pressure in the Arab culture, which emphasizes marriage and the ability to provide for the family financially as key social standards.

\section{Implications}

Health care administrators, especially nursing administrators, should consider the factors that contribute to job dissatisfaction and burnout and try to eliminate them by designing and implementing supportive policies and practices. A focus on meeting the personal and professional needs of the nursing cadre is paramount if quality health care services are to continue.

المجلة الصحية لشرق المتوسط، منظمة الصحة العالمية، المجلد الخامس عشر، العدد (،99.ب 
A third aspect that needs to be addressed is increasing continuing education programmes for nurses, especially programmes that deal with stress and anger management, enhance coping mechanisms, enhance personal skills and accomplishments, and update knowledge. Finally, more research is needed to extend the understanding of how the current political events and changing trends in health care affect the levels of job satisfaction and burnout among nurses in different settings.

\section{Conclusion}

Job satisfaction and burnout are clearly identified as problems in the area of human services that need to be addressed. Nevertheless, most researchers and practitioners believe that job satisfaction can be optimized and burnout minimized to enhance the quality of services to clients $[10,11,24]$. The results of this study should also be viewed in the context of the turbulent social, economic and political circumstances that prevail over the Middle East, and Palestine in particular. These circumstances can easily exacerbate the situation and can contribute to burnout and job dissatisfaction among all health care professionals. However, our findings do indicate that, despite hardships and turmoil, there are professionals who can benefit from the positive aspects of their profession, such as finding strength in their moral values, being content with the amount of professional responsibility they assume on a daily basis, having good relationships with their peers and superiors and finding their salary adequate to meet their living expenses and needs.

\section{Acknowledgements}

Our gratitude and thanks go to the University of Bethlehem for funding this research project through the internal research grant systemand to Mrs Hala Marzouka for the considerable work she did as part of the research project.

\section{References}

1. Dolan N. The relationship between burnout and job satisfaction in nurses. Journal of advanced nursing, 1987, 12:3-12.

2. Happell B et al. Job satisfaction and burnout: a comparative study of psychiatric nurses from forensic and a mainstream mental health service. International journal of mental health nursing, 2003, 12:39-47.

3. Arafa MA et al. Predictors of psychological well-being of nurses in Alexandria, Egypt. International journal of nursing practice, 2003, 9:313-20.

4. Blegen MA. Nurses' job satisfaction: a meta-analysis of related variables. Nursing research, 1993, 42(1):36-41.
5. Tovey EJ, Adams AE. The changing nature of nurses' job satisfaction: an exploration of sources of satisfaction in the 1990s. Journal of advanced nursing, 1999, 30(1):150-8.

6. McNeese-Smith DK. A content analysis of staff nurse descriptions of job satisfaction and dissatisfaction. Journal of advanced nursing, 1999, 29(6):1332-41.

7. Adams A, Bond S. Hospital nurses' job satisfaction, individual and organizational characteristics. Journal of advanced nursing, 1999, 29(6):536-43.

8. Pines A, Maslach C. Characteristics of staff burnout in mental health settings. 
Hospital and community psychiatry, 1978, 29(4):233-7.

9. Atencio BL et al. Nurse retention: is it worth it? Nursing economics, 2003, 21(6):262-8.

10. Lovgren $\mathrm{G}$ et al. Working conditions and the possibility of providing good care. Journal of nursing management, 2002, 10:201-9.

11. Kalliath $T$, Morris R. Job satisfaction among nurses: a predictor of burnout levels. Journal of nursing administration, 2002, 32(12):648-54.

12. Zuraikat N, McCloskey J. Job satisfaction among Jordanian registered nurses. International nursing review, 1986, 33(5):143-7.

13. Al-Ma'aitah $\mathrm{R}$ et al. Predictors of job satisfaction, turnover, and burnout in female and male Jordanian nurses. Canadian journal of nursing research, 1999, 31(3):15-30.

14. Misener $T$ et al. Toward an international measure of job satisfaction. Nursing research, 1996, 45(2):87-91.

15. Freudenberger H. Staff burnout. Journal of social issues, 1974, 30(1):159-65.

16. Pines $A$ et al. Burnout from tedium to personal growth. New York, Free Press, 1981.

17. Freudenberger H, Richelson G. Burnout: the high cost of high achievement. New York, Anchor Press, 1980.
18. Williams C. Empathy and burnout in male and female helping professionals. Research in nursing and health, 1989, 12(3):169-78.

19. Potter B. Overcoming job burnout: how to renew enthusiasm for work. Berkeley, Ronin Publishing, 1998.

20. Edwards D, Burnard P. A systematic review of stress and stress management interventions for mental health nurses. Journal of advanced nursing, 2003 , 42(2):169-200.

21. Maslow A. Motivation and personality. New York, Harper \& Row, 1940.

22. Maslach C, Jackson S. Maslach burnout inventory manual. Palo Alto, California, Consulting Psychologist Press, 1986.

23. Weiss D et al. Manual for the Minnesota Satisfaction Questionnaire. Minneapolis, University of Minnesota, Industrial Relations Center Bulletin 45, 1977 (Minnesota Studies in Vocational Rehabilitations 22).

24. Aiken LH et al. Hospital nurse staffing and patient mortality, nurse burnout, and job satisfaction. Journal of the American Medical Association, 2002, 288:198793.

25. Giacaman R. Health conditions and services in the West Bank and Gaza Strip. Geneva, United Nations, 1994.

26. Lama Y. Health services in the Occupied Territories. Rome, Ministry of Foreign Affairs, 1989. 